\title{
Optimal Real-time Static and Dynamic Air Quality Monitoring System
}

\author{
Najeeb Ullah 1,*, Faizullah Khan ${ }^{1}$, Abdul Ali Khan ${ }^{1}$, Surat Khan ${ }^{1}$, Abdul \\ Wahid Tareen ${ }^{1}$, Muhammad Saeed ${ }^{2}$ and Akbar Khan ${ }^{1}$
}

\author{
${ }^{1}$ Faculty of Information and Communication Technology, Balochistan University of \\ Information Technology Engineering and Management Sciences (BUITEMS), Quetta, \\ Pakistan \\ 2FAST National University of Computer and Emerging Sciences Islamabad, Pakistan; \\ muhammad.saeed@nu.edu.pk
}

\section{Article Type: Research Article \\ Article Citation: Najeeb Ullah, Faizullah Khan, Abdul Ali Khan, Surat Khan, Abdul Wahid Tareen, Muhammad Saeed, Akbar Khan. Optimal real-time static and dynamic air quality monitoring system. Indian Journal of Science and Technology. 2020; 13 (01), 91-102. D0l: 10.17485/ijst/2020/ v013i01/148375}

Received date: 0 ctober 22, 2019

Accepted date: December 19, 2019

*Author for correspondence: Najeeb Ullah \najeebullah.hasni@ gmail.com $\uparrow$ Faculty of Information and Communication Technology, Balochistan University of Information Technology Engineering and Management Sciences (BUITEMS), Quetta, Pakistan

\begin{abstract}
Objective: The objective of this study is to design and implement an effective low-cost air quality monitoring system that has the ability to monitor real-time air quality over a wide geographical area. Methodology: The proposed system is developed for $\mathrm{CO}$ and $\mathrm{NO}_{2}$. As a test case, our developed system is deployed in Quetta city, both in static and dynamic situations and the concentration level of $\mathrm{CO}$ and $\mathrm{NO}_{2}$ in the air are measured and stored, along with their time, date, and location. In order to analyze this information, the stored data are then transferred to a data collection center via short-range wireless communication. Findings: Many air quality monitoring systems exits in the market; however, most of these systems have several design limitations such as size, cost, inability to move, and demand for continuous internet connectivity. Therefore, in this study, we have designed and implemented an effective low-cost air quality monitoring system that has the ability to monitor real-time air quality over a wide geographical area. Moreover, unlike existing air quality monitoring systems, the proposed system does not require any continuous internet connection and it can monitor the concentration level of pollutants in the air both in a static position and in mobile situations. The test results show that our proposed system can perform very well in both static and mobile situations. Applications: The proposed monitoring mechanism can help environmental experts and the general public to develop a more robust strategy against the adverse effects of air pollution.
\end{abstract}

Keywords: Sensors, Pollution, Air-Quality, Global Positioning System (GPS), Zigbee. 


\section{Introduction}

It is believed that the earth is the only planet having air and water. Without air and water life is impossible on earth. Air pollution is one of the major problems nowadays and can affect the lives of millions [1-2]. There are many sources of air pollution, but most of the pollutants are produced by the emission of cars, buses, trucks forest fires.

Outdoor air pollution causes many health risks to the population living in and around urban areas. Indoor air pollution is caused by inefficient fuel combustion (Cooking, heating, and lighting), cleaning product usage and materials used in buildings (which produce chemical pollutants like radon). There are six common criteria air pollutants, such as Carbon monoxide (CO), Nitrogen Oxides ( $\mathrm{NOx})$, Lead $(\mathrm{Pb})$, Ozone $\left(\mathrm{O}_{3}\right)$, Particulate matter (PM), and sulfur dioxide $\left(\mathrm{SO}_{2}\right)$ [3-5]. The air we breathe in is not clean anymore. Air pollution causes many dangerous diseases to humans, like cancer, untimely death, lung diseases, disorders to children, damage to the respiratory system, asthma attacks, wheezing, coughing, and cardiovascular system problems [6-7]. Therefore, air pollution results in environmental degradation [8-9].

Pakistan is known to be the most urbanized country in South Asia, and its urban pollution causes many health risks. In Pakistan, the measured level of pollutants of sulfur dioxide $\left(\mathrm{SO}_{2}\right)$, Lead $(\mathrm{Pb})$, and Particulate matter $(\mathrm{PM})$ were recorded several times higher than the guidelines given by World Health Organization (WHO) during a time interval of 2006-2011. Nearly thirty-five percent of Pakistanis live in urban areas and most of them are under the threat of air pollution. Recent research depicts that, urban air pollution caused the death of more than twenty-two thousand and six hundred people in 2005 [10]. In Ref. [11], authors conducted research for Quetta city to explore air problems and diseases caused by air pollution. In their research, five thousand people were randomly selected to fill out a questionnaire about their health. They concluded that the main and dominant sources of air pollution in Quetta city are motor vehicles, home industries, power plants, and biological contents. The provision of real-time monitoring has become possible by the enhancement of sensors and embedded system [12]. Therefore, it is necessary to properly monitor the quality of air on a real-time basis, so that policymakers may be able to plan against the adverse effect of air pollution.

Many efforts have been carried out by the research community to contend air pollution [13]. In Ref. [14], authors have designed a mobile air quality monitoring system. Their system was based on a costly mechanism of Wi-Fi hotspot that was used for the transformation of data sensed by the sensors mounted on cars. The sensed data were then published on the map portal. In Ref. [15], authors presented an online General Packet Radio Service (GPRS) array for Air pollution monitoring and Vehicular Wireless Sensor Network (VSN) for Air pollution monitoring was proposed in Ref. [16]. GPRS array design was comprised of mobile sensing unit, sensor array, GPS and GPRS module, and pollution monitoring server. Monitored data were transmitted to the server by GPRS. The information was accessed by the public through the Web App [15]. Whereas, theVSN monitoring mechanism was based on GPS, GPRS/GSM modules. The sensed data were uploaded to the server through a short messaging service and the vehicles were connected through the Zigbee module [16]. As the performance of GPRS array and VSN design 
is mainly dependent on GSM, therefore, its performance is limited in terms of network coverage and accessed data size and rate.

Apart from these prototypes some of the prototypes need continuous internet connectivity. The designed proposed in Ref. [17] was based on the internet of things and was specifically designed to monitor the pollution by road vehicles for environment control agencies. In Ref. [18], authors proposed a centralized air pollution monitoring system; their system consisted of a sensor array, which may result in the redundancy of data. In Ref. [19], authors come up with a Mobile Sensing box deployed in a public transport and a personal sensing device.

They used public transport for the collection of concentration levels over fixed routes and the cellular modem was used for providing continuous internet connectivity. The design proposed in Ref. [20] was very useful in terms of cost and power as it can be used as a portable unit for monitoring the quality of air, however, it is lacking a centralized monitoring mechanism.

Since most of the previous work done in this area is useful in terms of finding air pollutants concentration. However, there are certain limitations associated with these designs, such as some researchers used very costly communication packages like GPRS, Wi-Fi shield, and cellular modem for uploading data to the server. While some prototypes are designed for fixed locations [21]. In order to cover a large geographical area, more prototypes are needed for air pollution monitoring. Besides these, some of the prototypes are designed for a single air pollutant element.

Therefore, the basic aim of this work is to design a portable cost-effective real-time air quality monitoringsystem for wide geographical areas, without the need for the internet. The system is being designed such that it stores the sensed data for a long period of time, before transmitting to the data collection entities. The stored data are then transmitted to data collection entities by the short-range wireless communication module. Data collection entities are further attached to the database server for the analysis of data. Provision of such information will enable the authorities (responsible for control and management of the environment), the individuals with health problems (such as respiratory problems, lung and heart diseases) to take necessary actions as per their requirementand of course it will be very beneficial for the general public to have real-time air pollution monitoring system in order to take precautionary measures of their health.

\subsection{Air-Quality Index}

Air-Quality Index (AQI) is an index for reporting daily air quality. It tells you how clean and unhealthy your air is, and what associated health effects might be a concern. The detailed information regarding the AQI is shown in Tables 1 and 2.

\section{Material and Methods}

\subsection{Hardware Implementation}

The proposed work uses road vehicles for the collection of data over their routes. Semiconductor gas sensor MQ-7 and MQ-135 have been interfaced, with Arduino Mega 
TABLE 1. Air Quality Index (AQI) [22]

\begin{tabular}{|c|c|c|}
\hline $\begin{array}{l}\text { Air-Quality Index levels } \\
\text { of health concern }\end{array}$ & $\begin{array}{l}\text { Numerical } \\
\text { value }\end{array}$ & Meaning \\
\hline Good & 0 to 50 & $\begin{array}{l}\text { Air quality is considered satisfactory and poses very } \\
\text { little or no risk. }\end{array}$ \\
\hline Moderate & 51 to 100 & $\begin{array}{l}\text { There may be moderate health risk concern for a } \\
\text { small number of people who are sensitive to air } \\
\text { pollution. }\end{array}$ \\
\hline Unhealthy & 101 to 250 & $\begin{array}{l}\text { The general public and member of a sensitive group } \\
\text { may observe unpleasant side effects. }\end{array}$ \\
\hline Very unhealthy & 251 to 500 & $\begin{array}{l}\text { A level that may have a very harmful impact on } \\
\text { the general public and members of people who are } \\
\text { sensitive to air pollution. }\end{array}$ \\
\hline
\end{tabular}

TABLE 2. The relationship between AQI and air pollutants [22]

\begin{tabular}{lcccc}
\hline Category description & Good & Moderate & Unhealthy & Very Unhealthy \\
\hline Values & $\mathbf{0 - 5 0}$ & $\mathbf{5 1 - 1 0 0}$ & $\mathbf{1 0 1 - 2 5 0}$ & $\mathbf{2 5 1 - 5 0 0}$ \\
$\mathrm{NO}_{2}(\mathrm{ppb})$ & $0-30$ & $31-60$ & $61-200$ & $201-2000$ \\
$\mathrm{CO}(\mathrm{ppm})$ & $0-2$ & $2.01-9$ & $9.01-15$ & $15.01-50$ \\
\hline
\end{tabular}

2560 powered by a battery (used as themain processing unit), to sense the concentration level of $\mathrm{CO}$ and $\mathrm{NO}_{2}$ in the air. In order to make the sensed data real-time, Real-Time Clock (RTC DS3231) is used with the Global Positioning System (GPS UART NEO-7M-C) to get the physical coordinate location along with time and date information for the sensed concentration level of air pollutants in ppm and ppb as shown in Figure 1. Arduino Mega has been programmed such that, it collects and processes the concentration level of air pollutants every two seconds. Arduino generates a string consisting of air pollutant levels, physical location, and time-date information. The string is then stored to the storing unit, San Disk Standard 16GB micro SD Memory Card which is attached to the main processing unit (see 1 to 17 of algorithm 1).

The stored data are then transmitted to data collection entities when the mobile device is in its proximity. A Microsoft Access (MS) database server is integrated into the data collection entities such as personal computers, mobile devices, and tablets for further analysis of data by interested users such as tourists, environmental agencies, and vehicle regeneration authorities as shown in Figure 2. The flowchart for hardware implementation is shown in Figure 3.

\subsection{Algorithm 1}
1: Start
2: if the Serial port is available then
3: Read serial port available
4: Check for String
5: if String is available then 


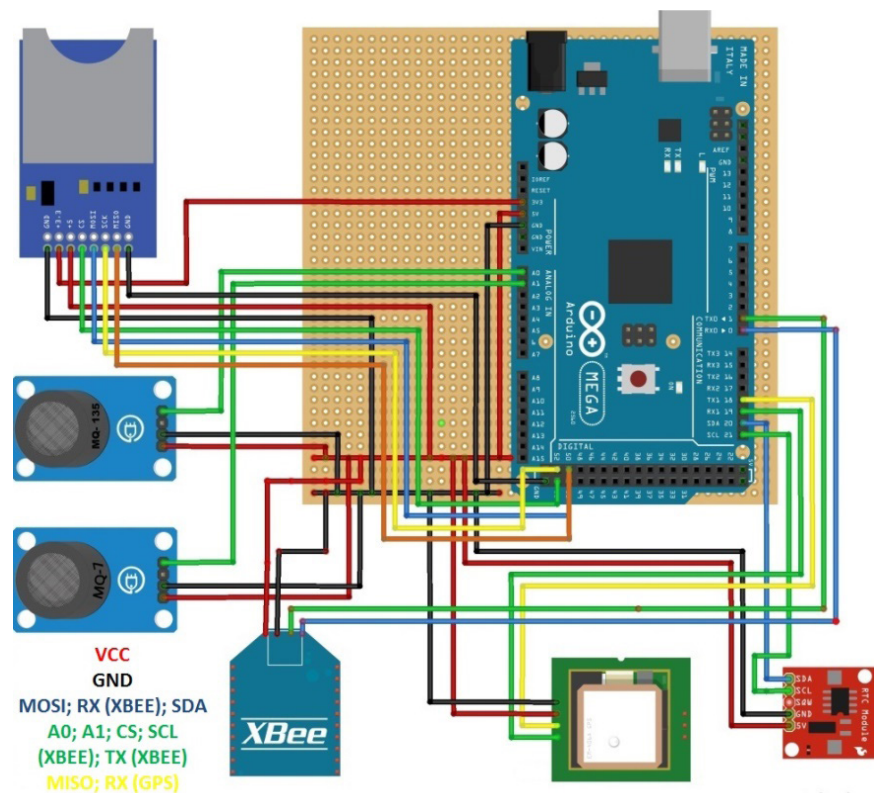

FIGURE 1. Hardware prototype designed for deployment in buses that travel through different routes of the city.

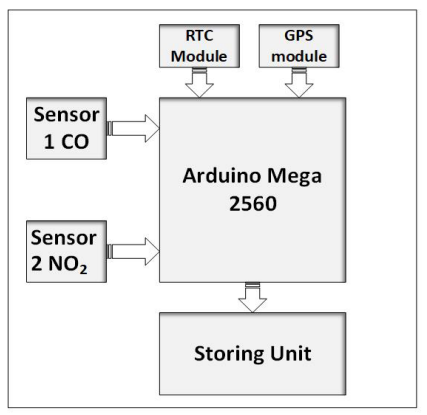

System Module

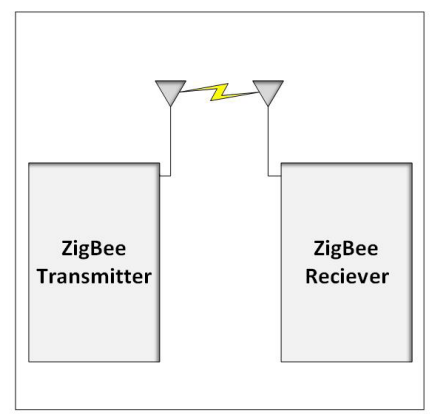

Short range wireless communication

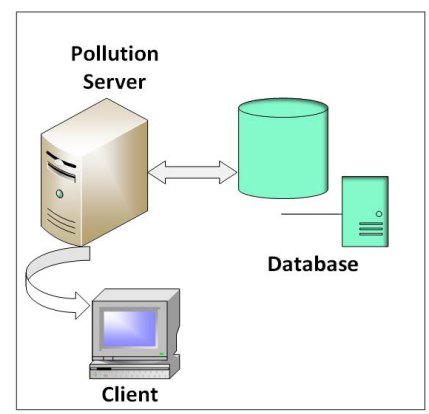

Pollution Server

FIGURE 2. Basic building blocks of the hardware system.

6: Read each string from SD card

7: Transmit string from the Zigbee module

8: else

9: Go to Step 4

10: endif

11: else

12: Read CO value

13: $\operatorname{Read} \mathrm{NO}_{2}$ values

14: Read the current time

15: Read the present coordinates

16: Encode Data into a string 


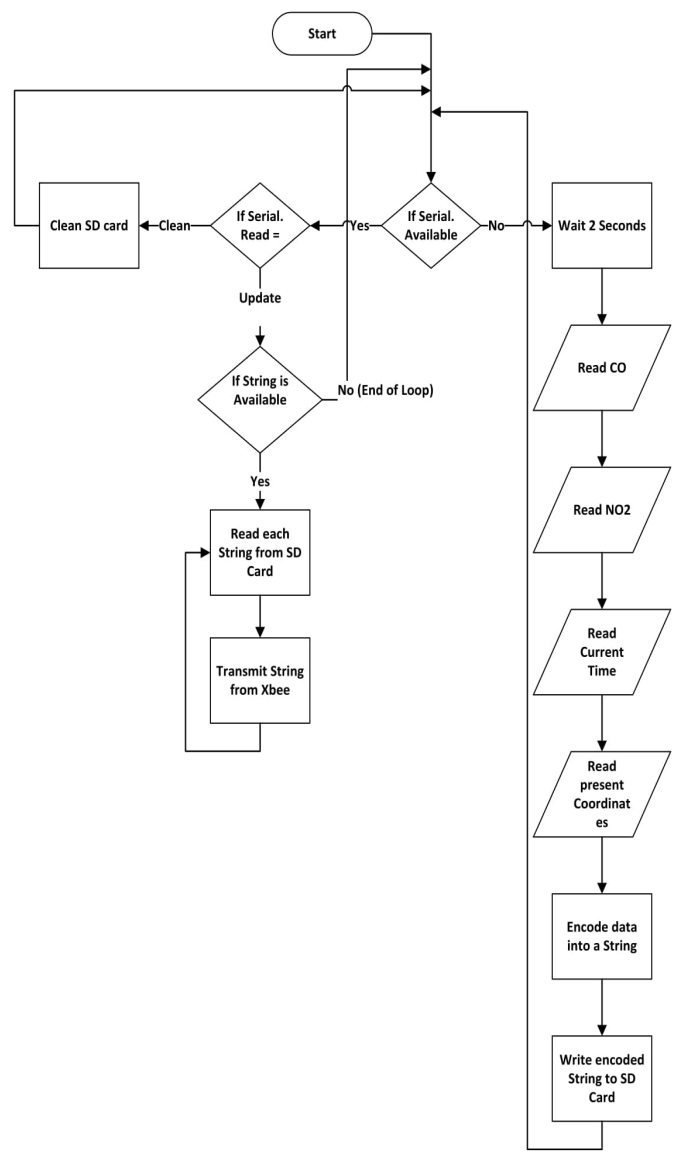

FIGURE 3. Flowchart for proposed hardware circuit.

17: Write an encoded string to SD card

18: Go to step 2

19: endif

\subsection{Flowchart of Hardware Implementation}

\subsection{Software Implementation}

The hardware prototype is interfaced with the Microsoft Access database through software named Quality Monitoring, created using Visual Studio 2012 as shown in Figure 4. The software is configured such that it acquires the string of data from the hardware through the Zigbee Module (see 1 to 8 of algorithm 2). After processing the data, the concentration level of gasses is stored in a database along with their time, date and location information for records (see 13 to 15 of algorithm 2).The complete received string is shown in Figure 5. The stored results may be analyzed at any time by pressing the reports button on the main window shown in Figure 4. The flowchart for software implementation is shown in Figure 6. 


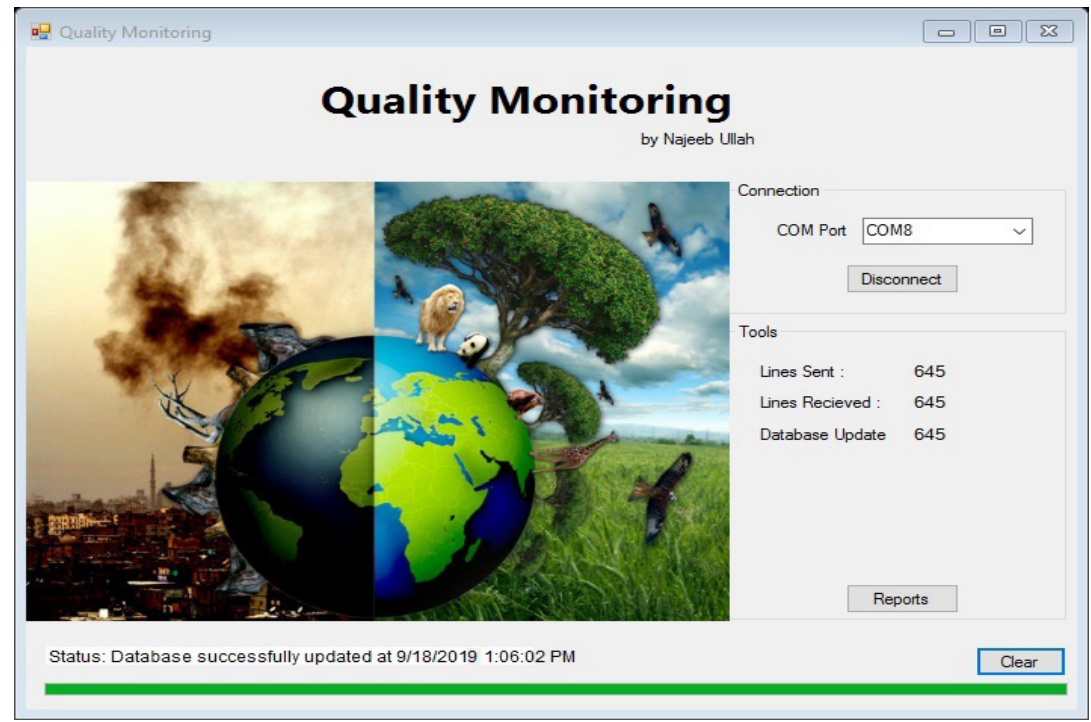

FIGURE 4. Main software window configured for the analysis of sensed data. The window also displays the string of received and sent data from the hardware prototype.

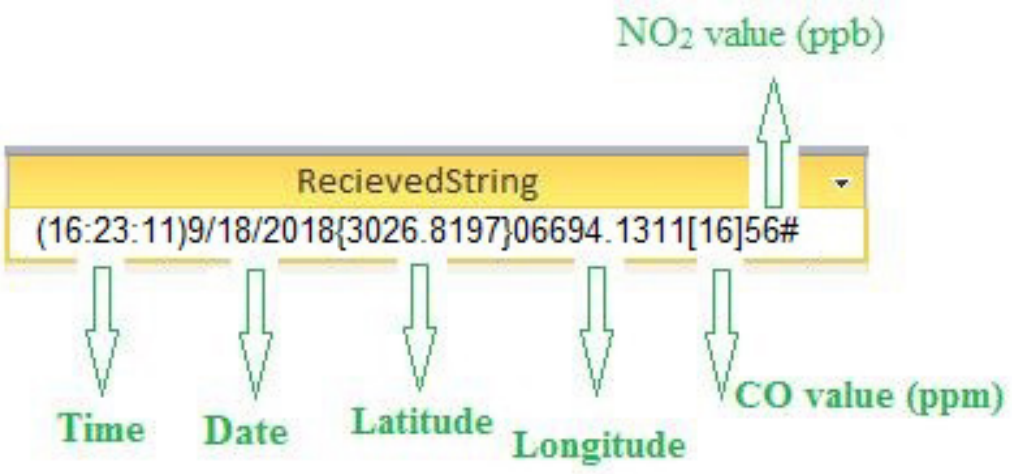

FIGURE 5. A received string of the hardware is decoded in the concentration level of carbon monoxide in parts per million (ppm) \& nitrogen dioxide in part per billion (ppb) along with their time date and location information.

\subsection{Algorithm 2}

1: Start

2: Set port information

3: Connect to Zigbee port

4: Make a request for "Update"

5: if Serial data is received then

6: Decode number of the incoming string

7: Calculate timer interval

8: Store each incoming string to an array

9: else 


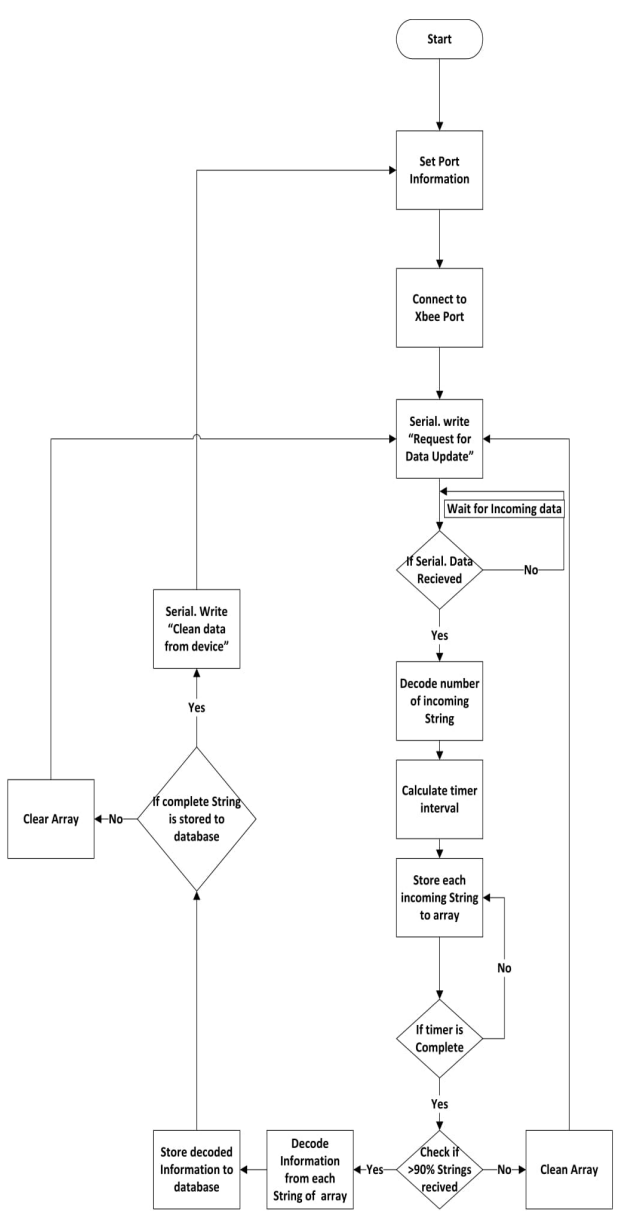

FIGURE 6. Flowchart for the proposed software design.

10: Wait for incoming data

11: Go to step 5

12: endif

13: if $>90 \%$ string received then

14: Decode information from each string of the array

15: Store decoded information to the database

16: if $>90 \%$ decoded information is stored to the database then

17: Clean data from the device

18: Go to step 2

19: else

20: Go to step 4

21: endif

22: else

23: Clean array

24: Go to step 4

25: endif 


\subsection{Flowchart of Software Implemsssssentation}

\section{Results and Discussion}

As our proposed system is portable, it can be used to monitor the concentration levels of pollutants both at the staticposition and mobile situations. Extensive experiments were carried out to obtain results for both scenarios.

\subsection{Static Position}

Firstly, the hardware system was installed at a fixed position at Jinnah road Quetta. The concentration levels of pollutants were measured on a daily basis, 24 hours for consecutive seven days. Figure 7 (a) and (b) shows the daily average of $\mathrm{CO}$ and $\mathrm{NO}_{2}$ concentration in the air for each day of the week.

As shown in Figure 7, there is almost no variation in the concentration level of $\mathrm{CO}$ and $\mathrm{NO}_{2}$. The fixed system at the static position can only monitor the concentration levels of pollutants in that specific region. And the environment of a specific location is almost constant until a sudden climate change occurs.

\subsection{Mobile Situations}

Secondly, for the mobile situation, the hardware system was deployed on the vehicle to measure the concentration of $\mathrm{CO}$ and $\mathrm{NO}_{2}$ in the air. Figure 8 shows the experimental results recorded on 18 September 2019, on the route from BUITEMS to Serena Hotel, Quetta. The heat map shows highly polluted areas for $\mathrm{CO}$ (a) and $\mathrm{NO}_{2}$ (b). The concentration gradient is divided into three different colors i.e. red, yellow, and green for high, moderate, and low intensities. Results obtained from the mobile situation show more variation as compared to the results obtained from a static position. The concentration of $\mathrm{CO}$ shows variation within this route, while the $\mathrm{NO}_{2}$ is high on the intersections of routes due to high traffic congestion.

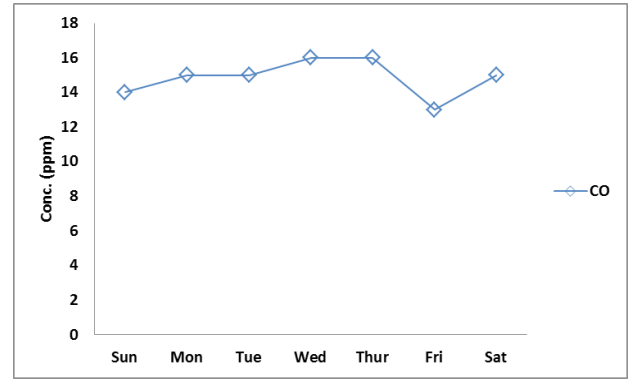

(a)

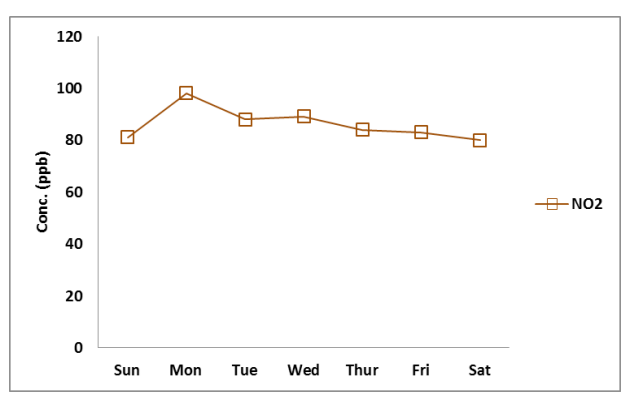

(b)

FIGURE 7. Daily average concentration of carbon monoxide (a) and nitrogen dioxide (b) in the air for consecutive seven days of a week, installed at a static position. 


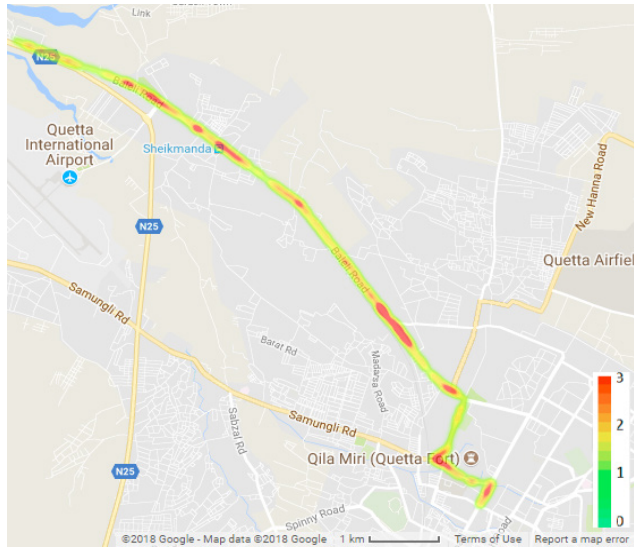

(a)

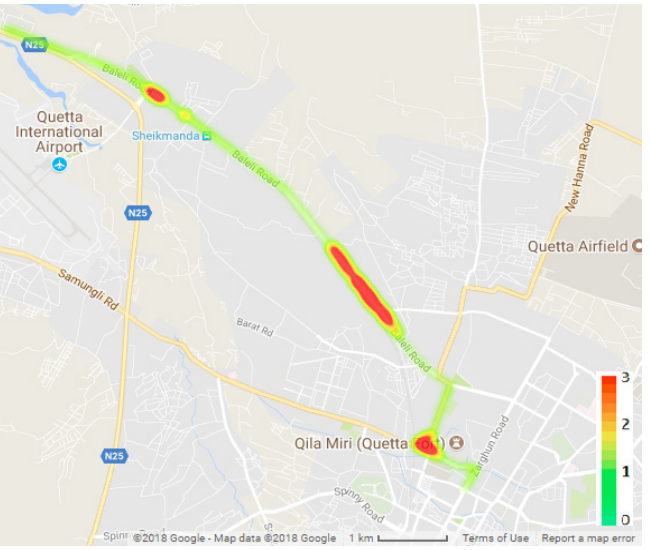

(b)

FIGURE 8. Heat map of carbon monoxide (a) and nitrogen dioxide (b) concentration on airport road, Quetta.

Furthermore, experimental results were obtained on the daily morning-evening basis for consecutive seven days for the same route. Figure 9(a) and (b) shows the morning, evening, and combined morning-evening average concentration of $\mathrm{CO}$ and $\mathrm{NO}_{2}$ in the air for each day of the week. It can be clearly seen from Figure 9 that there is a gradual increase in the concentration level of gases from Tuesday to Thursday (due to high traffic congestion on working days). And the minimum level of gases is achieved on Friday (due to low traffic congestion).

\section{Conclusions and Future Work}

A novel portable low-cost real-time air quality monitoring system was designed. And this system was implemented and tested in the city of Quetta, Pakistan. The proposed system stores the concentration level of gasses with time, date, and location information. The

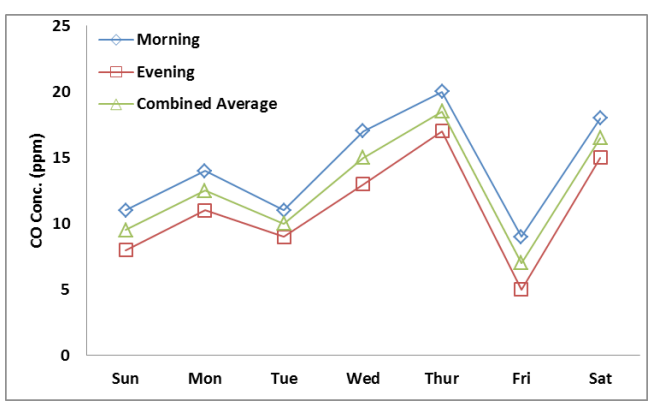

(a)

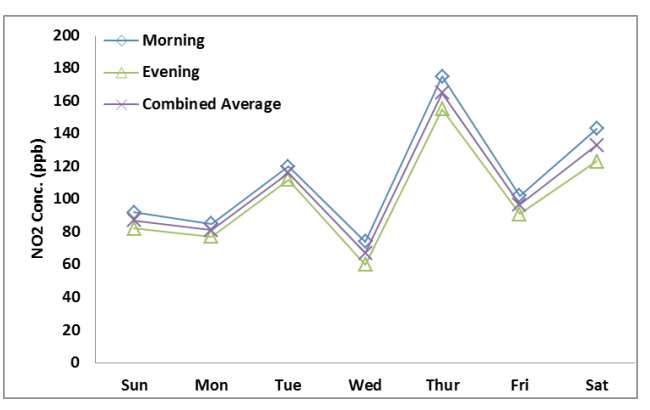

(b)

FIGURE 9. Morning, evening, and the combined morning-evening average concentration of carbon monoxide (a) and nitrogen dioxide (b) in the air for consecutive seven days of a week, on airport road, Quetta. 
sensed data were wirelessly transferred to data collection entities through Zigbee modules. The pollution database was also attached to the data collection entities for further analysis of pollution data. Extensive experimental results were obtained both for the static position and mobile situations. The real-time data of air quality through this system will make people able to take precautionary measures for their health and in addition, environmental management authorities to take necessary action against the adverse effect of air pollution. In the future, the concentration level of all the six criteria air pollutants can be monitored by interfacing more sensors to the system module. The atmospheric air pollution can be monitored seasonally, such as summer and winter.

\section{Acknowledgment}

The work presented in this study is a part of the postgraduate thesis of the principal author.

\section{References}

1. Fishbain B, Lerner. An evaluation tool kit of air quality micro-sensing units. Science of The Total Environment. 2017; 575, 639-648.

2. Sharma J, John S. Real time ambient air quality monitoring system. International Journal of Advances in Mechanical and Civil Engineering. 2017; 4(1), 72-74.

3. Kularatna N, Sudantha BH. An environmental air pollution monitoring system based on the IEEE1451 standard for low-cost requirements. IEEE Sensors Journal. 2008; 8(4), 415-422.

4. Suh $\mathrm{HH}$, Bahadori T. Criteria air pollutants and toxic air pollutants. Environmental Health Perspectives. 2000; 108(4), 625-633.

5. Rewatkar N, Khatri DM. Air pollution monitoring system using WSN. International Journal of Innovative Research in Science, Engineering and Technology. 2017; 6(11), 91-97.

6. Real-time air quality measurements using mobile platforms. https://rucore.libraries.rutgers. edu/rutgers-lib/46432/. Date accessed: 2015.

7. Ahmed MM, Banu S, Paul B. Real-time air quality monitoring system for Bangladesh's perspective based on internet of things. 2017 3rd international conference on electrical information and communication technology (ICT). 2017, 1-5.

8. Aziz A, Bajwa IU. Energy and pollution control opportunities for Lahore. WIT Transactions on The Built Environment. 2004; 75, 751-760.

9. Colbeck I, Nasir ZA, Ali Z. The state of ambient air quality in Pakistan-a review. Environmental Science and Pollution Research. 2010; 17 (1), 49-63.

10. Cleaning Pakistan's air: policy options to address the cost of outdoor air pollution. http:// documents.worldbank.org/curated/en/701891468285328404/Cleaning-Pakistans-air-policyoptions-to-address-the-cost-of-outdoor-air-pollution. Date accessed: 2014.

11. Ilyas SZ, Nasir SM, Raza SM. Air pollution problems and diseases caused by hazardous gases in Quetta, Pakistan. Journal of Applied Sciences and Environmental Management. 2008; 12(1), 123-126.

12. Marques G, Roque Ferreira C, Pitarma R. A system based on the internet of things for real-time particle monitoring in buildings. International Journal of Environmental Research and Public Health. 2018; 15(4), 821. 
13. Ali H, Soe JK, Weller SR. A real-time ambient air quality monitoring wireless sensor network for schools in smart cities. 2015 IEEE first international smart cities conference (ISC2). 2015, $1-6$.

14. Castell N, Dauge FR. Can commercial low-cost sensor platforms contribute to air quality monitoring and exposure estimates? Environment International. 2017; 99, 293-302.

15. Völgyesi P, Nádas A. Air quality monitoring with sensormap. IEEE computer society proceedings of the 7th international conference on Information processing in sensor networks. 2008, 529-530.

16. Al-Ali AR, Zualkernan I, Aloul F. A mobile GPRS-sensors array for air pollution monitoring. IEEE Sensors Journal. 2010; 10(10), 1666-1671.

17. Hu SC, Wang YC. A vehicular wireless sensor network for CO2 monitoring. In: Sensors. 2009, 1498-1501.

18. Rushikesh R, Sivappagari CMR. Development of IoT based vehicular pollution monitoring system. 2015 international conference on green computing and internet of things (ICGCIoT). 2015, 779-783.

19. Bhagwan GV, Puranik VG. Real-time air pollution monitoring using a mobile phone. International Journal of Innovative Research in Science, Engineering and Technology. 2014; 3(4), 447-453.

20. Real-time air quality monitoring through mobile sensing in metropolitan areas. https://dl.acm. org/citation.cfm?id=2505834. Date accessed: 2013.

21. Hasenfratz D, Saukh O. Participatory air pollution monitoring using smartphones. Mobile Sensing. 2012; 1, 1-5.

22. Choi J. Harmful impact of air pollution on severe acute exacerbation of chronic obstructive pulmonary disease: particulate matter is hazardous. International Journal of Chronic Obstructive Pulmonary Disease. 2018; 13, 1053-1059. 